ORIGINAL ARTICLE

\title{
What determines patients' satisfaction with their mental health care and quality of life?
}

\author{
P Blenkiron, C A Hammill
}

Postgrad Med J 2003;79:337-340

See end of article for authors' affiliations

Correspondence to: Dr Paul Blenkiron, Department of Adult Psychiatry, Bootham Park Hospital, Bootham, York YO30 7BY, UK; paul.blenkiron@excha yhs-tr.northy.nhs.uk

Submitted

19 December 2002

Accepted

28 February 2003

\begin{abstract}
Objectives: This study investigated whether patients' satisfaction with their mental health care and quality of life is related to their age, gender, psychiatric diagnosis, and duration of mental disorder. Method: 120 adults of working age who were receiving input from a community mental health team in North Yorkshire were invited to complete the Carers' and User's Expectations of Services, User Version (CUES-U) questionnaire. This 16 item self rated outcome measure covers the issues that those using mental health services have identified as being their priorities.

Results: CUES-U ratings were lowest for "Social life" (49\% satisfied) and highest for "Relationships with physical health workers" (88\% satisfied). Satisfaction with psychiatric services correlated significantly with patients' age (Spearman's $r=0.444, p<0.001$ ) and their satisfaction in other areas of their lives such as housing, money, and relationships $(r=0.575, p<0.001)$. Those with psychotic disorders rated their quality of life as higher than other respondents (median total satisfaction score $12 \vee 9$, Mann-Whitney $U=377, p=0.001)$. Gender and duration of disorder were unrelated to service satisfaction.

Conclusions: Patient satisfaction ratings have been promoted as an outcome measure when evaluating the quality of their mental health services. Certain factors influencing an individual's satisfaction with the care provided (such as their age and general quality of life) are not directly under the control of professionals.
\end{abstract}

atient satisfaction ratings are increasingly promoted as an indicator of quality of care. ${ }^{1}$ However, satisfaction scores do not take account of differences between patients that may be due to sociodemographic characteristics or type of illness rather than the quality of service delivered. ${ }^{2}$

"Patient and carer experience" is one of the main areas identified for determining performance in the government's National Service Framework for Mental Health. ${ }^{3}$ Mental health focus groups believe that a reliance on psychiatric symptoms alone as a measure of service satisfaction is too narrow a concept. ${ }^{4}$ Quality of life is a strong predictor of psychological wellbeing, ${ }^{5}$ and people with mental illness are believed to experience lower life satisfaction than the population as a whole. ${ }^{6}$

A Medline literature search 1966 to 2002 revealed that the factors which determine satisfaction with mental health services remain greatly under-researched. ${ }^{6-8}$ Studies have often been hampered by the quality and validity of the instruments used. ${ }^{910}$ Some investigators have found that an individual's satisfaction with mental health care is correlated with their age and global subjective quality of life, but not psychotic symptoms, insight, or attitudes to treatment. ${ }^{11}$ Others, in contrast, have found no relationship between satisfaction and age or living conditions. ${ }^{2}$

The purpose of this study was to determine whether patients' satisfaction with their mental health care and general quality of life is related to their age, gender, psychiatric diagnosis, and duration of illness. A recently validated satisfaction instrument was chosen, the Carers' and Users' Expectations of Service, User Version (CUES-U). ${ }^{13}$ It was developed as a result of a collaboration between the National Schizophrenia Fellowship, the Royal College of Nursing Institute, the University of East Anglia School of Social Work, and the Royal College of Psychiatrists' Research Unit. CUES-U is important because it covers the issues of quality of life and satisfaction with mental health services that patients, rather than professionals, have identified as being their priorities. ${ }^{14}$

\section{SUBJECTS AND METHODS}

CUES-U is a self rated 16 item booklet. It assesses seven key quality of life areas ("Where you live", "Money", "Help with Finances", "How you spend your day", "Family and friends", "Social life", and "Stigma and discrimination") and nine areas of mental healthcare delivery ("Information and advice", "Access to mental health services", "Choice of mental health services", "Relationships with mental health workers", "Consultation and control", "Advocacy", "Medication", "Access to physical health services", and "Relationship with physical health workers". Each area contains two main questions. Part A ("comparison") gives a normative statement describing the situation if there was no problem arising. For example, Money: "You should have enough money to pay bills, stay out of debt and not miss meals. You should not have to feel isolated or cut off from society because of lack of money". The respondent is then asked how their situation compares with this (as good as this, worse, or very much worse than this). Part B ("satisfaction") questions whether the respondent is satisfied (yes, unsure, or no) with the issue described (table 1).

The professionals participating in this study were members of a community mental health team in North Yorkshire serving a semirural population of 64000 . They included two psychiatrists, three community psychiatric nurses, two social workers, and one occupational therapist. A total of 120 patients were prospectively identified for recruitment from the mental health team records.

They were included in the study if aged between 16 and 65 years, and had a mental health disorder of greater than six months' duration, for which they were currently receiving input from at least one mental health professional as part of the care programme approach. ${ }^{15}$

After an introductory training workshop facilitated by the Royal College of Psychiatrists Research Unit, professionals gave a copy of CUES-U, together with a letter of explanation, to patients who were attending for normal clinical care. In order to reduce bias, respondents were asked to complete 
Table 1 CUES-U and part B satisfaction questions

\begin{tabular}{|c|c|}
\hline \multicolumn{2}{|l|}{ Quality of life } \\
\hline 1. Where you live & Are you satisfied with the place you live in? \\
\hline 2. Money & $\begin{array}{l}\text { Do you have enough money to meet your } \\
\text { basic needs? }\end{array}$ \\
\hline 3. Help with finances & $\begin{array}{l}\text { Are you satisfied with the level of help you } \\
\text { get with your finances? }\end{array}$ \\
\hline 4. How you spend your day & $\begin{array}{l}\text { Are you satisfied with the way you spend } \\
\text { your day? }\end{array}$ \\
\hline 5. Family and friends & $\begin{array}{l}\text { Are you satisfied with your relationships with } \\
\text { the people closest to you? }\end{array}$ \\
\hline 6. Social life & Are you satisfied with your social life? \\
\hline 7. Stigma and discrimination & $\begin{array}{l}\text { Are you satisfied with the way other people } \\
\text { treat you? }\end{array}$ \\
\hline \multicolumn{2}{|l|}{ Mental health service } \\
\hline 1. Information and advice & $\begin{array}{l}\text { Are you satisfied with the information and } \\
\text { advice you get? }\end{array}$ \\
\hline 2. Access to mental health services & $\begin{array}{l}\text { Are you satisfied with your ability to get } \\
\text { help when you need it? }\end{array}$ \\
\hline 3. Choice of mental health services & $\begin{array}{l}\text { Are you satisfied with the range of choice } \\
\text { you have? }\end{array}$ \\
\hline 4. Relationships with mental health workers & $\begin{array}{l}\text { Are you satisfied with your relationships with } \\
\text { mental health workers? }\end{array}$ \\
\hline 5. Consultation and control & $\begin{array}{l}\text { Are you satisfied with the level of } \\
\text { consultation and control you have? }\end{array}$ \\
\hline 6. Advocacy & $\begin{array}{l}\text { Are you satisfied with the help you get in } \\
\text { difficult situations? }\end{array}$ \\
\hline 7. Your drug treatment & $\begin{array}{l}\text { Are you satisfied with your current } \\
\text { medication? }\end{array}$ \\
\hline 8. Access to physical health services & $\begin{array}{l}\text { Are you satisfied with your access (GP, } \\
\text { hospital, dentist, optician, chiropodist)? }\end{array}$ \\
\hline 9. Relationships with physical health workers & $\begin{array}{l}\text { Are you satisfied with the way your physical } \\
\text { problems are dealt with? }\end{array}$ \\
\hline
\end{tabular}

CUES-U without the assistance of mental health professionals. They were encouraged to seek help from family or friends if they had difficulties filling in the booklet. They were also given contact details for an independent advocacy service provided through the local mental health resource centre for support in expressing their views. Patients were requested to return CUES-U after that or the next clinical meeting. Participation was voluntary, and booklets were number coded to preserve anonymity. Mental health professionals were instructed to review the replies with their patient in session, in order to improve the individual's clinical care. They also completed a standardised questionnaire recording the patient's age, gender, duration of mental disorder, and diagnostic category according to the 10th edition of the International Classification of Diseases, ${ }^{16}$ before returning the booklets to a local data collection point.

Data analysis was performed using the Statistical Package for Social Sciences version 10.0. Four "total CUES-U" scores were calculated by adding together individual groups of responses for quality of life items and service delivery items. For part A questions, this gave a "life comparison score" ( seven items, maximum $=14$ ) and a "service comparison score" (nine items, maximum $=18$ ). For part B questions, a "life satisfaction score" ( seven items, maximum $=14$ ) and a "service satisfaction score" (nine items, maximum $=18$ ) were obtained. As the CUES-U responses were categorical or ordinal, non-parametric statistical tests were applied.

\section{RESULTS}

The CUES-U booklets were fully completed and returned by $86(72 \%)$ patients.

Table 2 describes the characteristics of responders and nonresponders comprising the study population. The diagnostic category of psychosis includes schizophrenia, non-affective paranoid psychosis, and delusional disorders. Satisfaction with the quality of life items ranged from $62 \%$ (social life) to $77 \%$ (where you live) for part A questions and from 49\%

\begin{tabular}{|c|c|c|}
\hline Characteristic & $\begin{array}{l}\text { Responders } \\
(n=86)\end{array}$ & $\begin{array}{l}\text { Non-responders } \\
(\mathrm{n}=34)\end{array}$ \\
\hline Gender (\% females) & $44(51)$ & $17(50)$ \\
\hline Ethnicity (\% white caucasian) & $86(100)$ & $34(100)$ \\
\hline Mean (SD) age & $44.3(12.6)$ & $43.9(10.6)$ \\
\hline Range & $17-65$ & $23-64$ \\
\hline \multicolumn{3}{|l|}{ Diagnosis } \\
\hline Psychosis including schizophrenia & $25(29)$ & $12(35)$ \\
\hline Manic depressive (bipolar) disorder & $9(11)$ & $2(6)$ \\
\hline Unipolar depression & 25 (29) & $9(26)$ \\
\hline Anxiety (including panic and phobias) & $14(16)$ & $3(9)$ \\
\hline Personality disorder & $6(7)$ & $4(12)$ \\
\hline Other & 7 (8) & $4(12)$ \\
\hline \multicolumn{3}{|l|}{ Duration of disorder (years) } \\
\hline$<1$ & $6(7)$ & $2(6)$ \\
\hline $1-5$ & $35(41)$ & $11(32)$ \\
\hline$>5$ & $45(52)$ & $21(62)$ \\
\hline
\end{tabular}

( social life) to $77 \%$ (where you live) for part B questions. Satisfaction with health services ranged from 73\% (choice and access to mental health services) to $88 \%$ (relationship with physical health workers) for part A questions and from $72 \%$ (access to mental health services) to $86 \%$ (relationship with physical health workers) for part B questions.

The total median scores (interquartile range) were 13 (1014) for life comparison, 11 (8-14) for life satisfaction, 18 (1618) for service comparison, and 17 (15-18) for service satisfaction. The comparison (part A) responses correlated significantly with the satisfaction (part B) responses (Spearman's $r=0.863, \mathrm{p}<0.001)$. Total service satisfaction scores correlated significantly with total life satisfaction scores $(r=$ $0.575, \mathrm{p}<0.001)$, total life comparison scores $(r=0.468$, $\mathrm{p}<0.001)$, and total service comparison scores $(r=0.849$, $\mathrm{p}<0.001)$. 


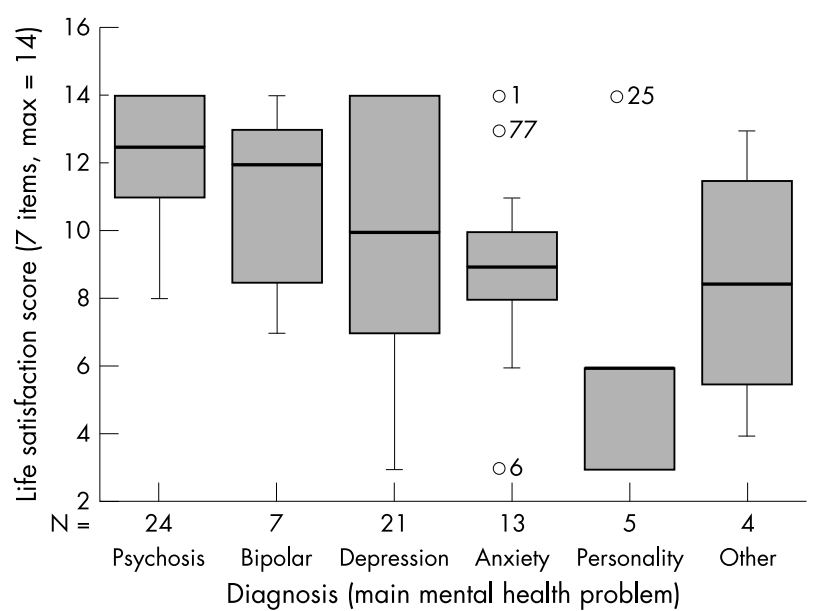

Figure 1 Life satisfaction scores according to psychiatric disorder. The shaded box area is the interquartile range, containing $50 \%$ of the values; the dark line across the box is the median; the "whiskers" extend to the largest and smallest values within 1.5 box lengths; the width of the box does not represent anything; and circles represent outliers.

\section{Age}

A patients' age was significantly related to their total scores for service comparison $(r=0.356, \mathrm{p}=0.003)$ and service satisfaction $(r=0.444, \mathrm{p}<0.001)$ responses but not to their scores for life comparison $(r=0.186, \mathrm{p}=0.12)$ or life satisfaction $(r=0.208, \mathrm{p}=0.08)$. For example, the median age of those satisfied with their psychotropic drug treatment was 45 years compared with 37 years for those who were dissatisfied (Mann-Whitney $\mathrm{U}=386.5, \mathrm{p}=0.04$ ).

\section{Gender}

Patient's gender was not related to their satisfaction or comparison ratings regarding quality of life or service provision. The total median score for service satisfaction was 17 for both men and women (Mann-Whitney $\mathrm{U}=665, \mathrm{p}=$ $0.99)$.

\section{Duration of mental disorder}

The duration of an individual's mental health problems was not related to their service satisfaction scores. However, those patients whose mental disorder had lasted more than five years ( 45 cases, $52 \%$ ) were more satisfied with their quality of life than those with more acute disorders (median total life satisfaction score $12 v 9$, Mann-Whitney $\mathrm{U}=481, \mathrm{p}=0.026$ ). Cases involving mental disorders present for over five years included a significantly higher proportion of psychotic and bipolar disorders (26/44 patients, 59\%) compared with patients with disorders of a shorter duration $\left(8 / 40,20 \%, \chi^{2}\right.$ 13.3, $\mathrm{df}=1, \mathrm{p}<0.001)$. No significant correlation was found between age and duration of mental disorder $(r=0.08, \mathrm{p}=$ $0.47)$.

\section{Diagnosis}

Total satisfaction scores for patients according to their psychiatric diagnosis are shown as box plot presentations in fig 1 (quality of life) and fig 2 (mental health services). The median satisfaction ratings were highest for those with psychotic, bipolar, and depressive disorders. Those with personality disorders were less satisfied with both their life and mental health services.

A post hoc analysis of satisfaction scores was performed according to whether patients had a psychotic diagnosis (including schizophrenia and bipolar disorder, $\mathrm{n}=34$ ) compared with a non-psychotic diagnosis (anxiety, depression, personality disorder, or other non-psychotic disorder, $\mathrm{n}=$ 52). Regarding satisfaction with mental health services, no

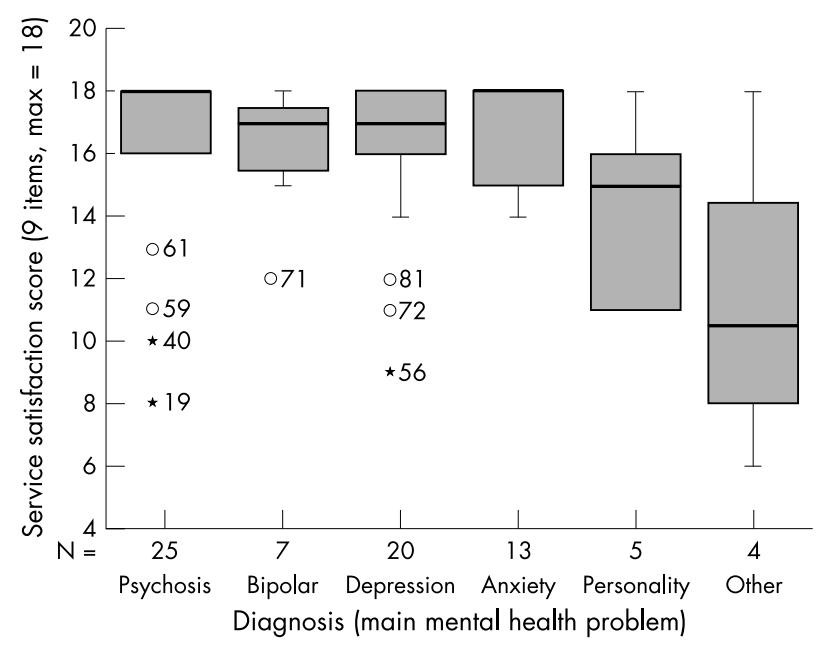

Figure 2 Service satisfaction scores according to psychiatric disorder. The shaded box area is the interquartile range, containing $50 \%$ of the values; the dark line across the box is the median; the "whiskers" extend to the largest and smallest values within 1.5 box lengths; the width of the box does not represent anything; and circles represent outliers and asterisks represent extremes for individual variables.

statistically significant difference was found (median score 18 for psychotic versus 17 for non-psychotic categories, MannWhitney $U=564, p=0.213)$. However, those with psychotic disorders rated their quality of life as significantly better than other respondents (median total satisfaction score $12 \vee 9$, Mann-Whitney $\mathrm{U}=377, \mathrm{p}=0.001$ ).

\section{DISCUSSION}

This study found that older age, the presence of major mental illness and perceived general quality of life are associated with a greater satisfaction with mental health services. Quality of life ratings were also higher in those with a psychotic diagnosis and those with mental health problems of a longer duration.

The generally high levels of satisfaction expressed in this study are similar to those found in previous research using both mental ${ }^{17}$ and physical ${ }^{18}$ illness populations. Those with a diagnosis of psychosis, bipolar or unipolar depression all expressed moderately high levels of satisfaction for both their life and their mental health care. This may indicate that psychiatric services are being appropriately targeted towards those with severe and enduring mental illness, in keeping with the main aims of community mental healthcare reform in the United Kingdom. ${ }^{19}$ Conversely, the lower satisfaction scores seen in those with personality disorders are consistent with their common clinical presentation, which may include subjective complaints of boredom with aspects of life or dissatisfaction in personal or clinical relationships.

Older patients were significantly more satisfied with their mental health care. One possible explanation for this finding is a cohort effect, with younger generations having greater expectations and older patients perceiving a greater sense of duty not to complain about the services offered. Alternatively, a drop out effect may be operating, so that those who are happy with their care are tending to remain in contact over time. In support of this hypothesis, previous research has shown that patients who inappropriately disengage from services are more likely to be younger. ${ }^{20}$ It is also possible that some respondents are continuing to engage with services not because of greater satisfaction, but because they are hoping that their workers will eventually find appropriate solutions to their difficulties. However, this study found no significant relationship between a patient's age and the duration of their 
mental disorder. Moreover, the increased quality of life ratings in those with longstanding mental health problems compared with those of more recent onset suggests the occurrence of clinical improvement in their mental health over time, or at least an functional adaptation to and acceptance of the relevant disability.

There are several methodological limitations to the above findings. First, the high levels of the satisfaction scores could be producing a "ceiling effect" masking any potential differences between patients. Second, respondents knew that their replies would be seen later by their main mental health professional, when discussing individual improvements to the standard of clinical care. Third, there is the possibility of a selection bias among responders, given a lack of data on satisfaction for the 34 patients who did not return CUES-U questionnaires. However, there is some evidence indicating that those who completed the study were not a selected group of compliant and satisfied customers. The sample population was predetermined at the outset using mental health records rather than clinically, and patient demographic data in table 2 is similar for both responders and non-responders. In addition, the range of satisfaction scores obtained in this study ( $49 \%$ to $88 \%$ ) is comparable to that found during field trials for the CUES-U questionnaire $(40 \% \text { to } 74 \%)^{13}$ in other clinical populations.

Satisfaction with mental health services correlated significantly with satisfaction in other areas of patients' lives such as housing, money, social life, and relationships. A recent study of individuals suffering from chronic arthritis or diabetes found that physical health status and whether patients were seeing a primary or secondary care physician explained only a small proportion (less than $10 \%$ ) of the total variation in satisfaction with their care. ${ }^{18}$ Similarly, Ruggeri and colleagues found that diagnosis, disability, and functioning explained less than $14 \%$ of the variance in quality of life profile in patients with a mental health disorder. ${ }^{21}$ They did, however, note that service satisfaction, more than any other health indicator, was linked to relationships, leisure activities, and general wellbeing. This study adds to these research findings by confirming that the general quality of an individual's life circumstances is closely linked to their satisfaction with mental health care. Despite recent attempts to integrate mental health services and social care provision, ${ }^{22}$ many of the factors affecting patients' quality of life remain beyond the direct control of health professionals.

\section{ACKNOWLEDGEMENTS}

We thank the professionals and patients from Selby District Community Mental Health Services who participated in this study. We are also grateful to Paul Lelliott, Kim McLellan, and Maureen McGeorge from the Royal College of Psychiatrists Research Unit for their support. The complete CUES-U instrument is protected by Crown copyright. Further information on CUES is available from the Royal College of Psychiatrists' Research Unit, 83 Victoria Street, London SW1H 0HW, UK (ww.rcpsych.ac.uk/cru).

\section{Authors' affiliations}

P Blenkiron, C A Hammill, Department of Adult Psychiatry, Bootham Park Hospital, York

\section{REFERENCES}

1 Rea CA, Rea DM. Managing performance and performance management: information strategy and service user involvement. Journal of Management in Medicine 2002;16:78-93.

\section{Learning points}

- Symptom severity and degree of functional disability account for only a small proportion of the variation in patients' satisfaction with their health services.

- The moderately high levels of satisfaction with mental health services found in this study are related to an individual's age, but not their gender or the duration of their mental disorder.

- Those with a psychotic disorder (schizophrenia or bipolar disorder) express higher levels of satisfaction with their quality of life than those with anxiety or personality disorders. However, around half of all respondents are discontent with their social life and how they spend their day.

- Patients who are happy with aspects of their life such as housing, finances, and relationships with family and friends are significantly more likely to be satisfied with the community mental health and primary care services provided.

2 Hoff RA, Rosenheck RA, Meterko M, et al. Mental illness as a predictor of satisfaction with inpatient care at Veterans Affairs hospitals. Psychiatric Services 1999:50:680-5.

3 Department Of Health. A national service framework for mental health London: Department of Health, 1999.

4 Powell RA, Single HM, Lloyd KR. Focus groups in mental health research: enhancing the validity of user and provider questionnaires. Int $J$ Soc Psychiatry 1996;42:193-206.

5 Christopher KA. Determinants of psychological well-being in Irish immigrants. West I Nurs Res 2000:22:123-40.

6 Holley H. Quality of life measurement in mental health. Introduction and overview of workshop findings. Canadian Journal of Community Mental Health 1998;3(suppl):9-21

7 Lovell K. User satisfaction with in-patient mental health services. Journal of Psychiatric Mental Health Nursing 1995;2:143-50.

8 Blenkiron P. Referral to a psychiatric clinic: what do patients expect? International Journal of Health Care Quality Assurance 1998:11:188-92.

9 Noble LM, Douglas BC, Newman SP. What do patients expect of psychiatric services? A systematic and critical review of empirical studies. Soc Sci Med 2001;52:985-98.

10 Barker DA, Orrell MW. The psychiatric care satisfaction questionnaire: a reliability and validity study. Soc Psychiatry Psychiatr Epidemiol 1999:34:111-16.

11 Holloway F, Carson J. Subjective quality of life, psychopathology, satisfaction with care and insight: an exploratory study. Int J Soc Psychiatry 1999;45:259-67.

12 Eklund E, Hansson L. Determinants of satisfaction with community-based psychiatric services: a cross-sectional study among schizophrenia outpatients. Nordic Journal of Psychiatry 2001;55:413-8.

13 Lelliott P, Beevor A, Hogman G, et al. Carers' and users' expectations of services-user version (CUES-U): a new instrument to measure the experience of users of mental health services. Br J Psychiatry 2001; 179:67-72

14 Lelliot P. What do people want from specialist mental health services and can this be measured in routine settings? Behavioural and Cognitive Psychotherapy 2000;28:361-8

15 Department of Health. Effective care co-ordination in mental health. Modernising the care programme approach. London: Department of Health, 2000

16 World Health Organisation. The ICD-10 classification of mental and behavioural disorders. 10th edition. Geneva: WHO 1992

17 Perera H, Perera R. User satisfaction with child psychiatry outpatien care: implications for practice. Ceylon Med J 1998;43:185-90.

18 Bidaut-Russell M, Gabriel SE, Scott CG, et al. Determinants of patient satisfaction in chronic illness. Arthritis Rheum 2002;47:494-500.

19 Barr W, Huxley P. The impact of community mental health reform on service users: a cohort study. Health and Social Care in the Community 1999:7:129-39.

20 Rossi A, Amaddeo F, Bisoffi G, et al. Dropping out of care: inappropriate terminations of contact with community-based psychiatric services. Br J Psychiatry 2002;181:331-8

21 Ruggeri M, Gater R, Bisoffi G, et al. Determinants of subjective quality of life in patients attending community-based mental health services. The South-Verona Outcome Project 5. Acta Psychiatr Scand 2002:105:131-40

22 Kennedy P. Is psychiatry losing touch with the rest of medicine? Advances in Psychiatric Treatment 2000;6:16-21. 